\title{
PEDIATRIC ORIGINAL ARTICLE \\ 30-year trends in overweight, obesity and waist-to-height ratio by socioeconomic status in Australian children, 1985 to 2015
}

\author{
LL Hardy ${ }^{1}$, S Mihrshahi ${ }^{1}$, J Gale ${ }^{1}$, BA Drayton ${ }^{2}$, A Bauman ${ }^{1}$ and J Mitchell ${ }^{2}$
}

BACKGROUND/OBJECTIVE: To report 30-year (1985-2015) prevalence trends in overweight, obesity and abdominal obesity among children by school level and socioeconomic status (SES).

SUBJECTS/METHODS: Five cross-sectional, population child surveys (age 4-18 years; $n=27$ 808) conducted in 1985-1997-20042010-2015 in New South Wales, Australia. Outcomes were prevalence of measured overweight, obesity and waist-to-height ratio $(\mathrm{WH} t \mathrm{R} \geqslant 0.5)$ by sex, school level (children (primary) and adolescents (high)) and SES tertile.

RESULTS: In 2015, the prevalences of overweight, obesity and WHtR $\geqslant 0.5$ in children were $16.4 \%, 7.0 \%$ and $14.6 \%$, respectively, and in adolescents $21.9 \%, 17.2 \%$ and $4.6 \%$, respectively. Obesity prevalence has not significantly changed in children or adolescents since 1997, nor since 2010 (children, $P=0.681$; adolescents, $P=0.21$ ). Overweight has not significantly changed in children since 1997, but has in adolescents since 1985, with a relative increase of 16 percentage points $(P<0.001)$ between 2010 and 2015 . WHtR $\geqslant 0.5$ prevalence has significantly changed since 1985, except in adolescent girls between 2010 and 2015 . Between 2010 and 2015 the relative increase in WHtR $\geqslant 0.5$ was 17 and 40 percentage points in children and adolescent boys, respectively. Significant disparities in prevalence rates between children and adolescents from low and high SES backgrounds began in 2010 for overweight, since 1997 for obesity and since 2004 for WHtR $\geqslant 0.5$. Differences between SES groups have become larger over the past 18 years.

CONCLUSIONS: Since 1997, obesity has remained stable, and overweight has stabilized in children, not in adolescents. WHtR $\geqslant 0.5$ significantly increased between 1985 and 2015, with prevalence rates at each survey around twice the obesity prevalence.

Compared with high SES children and adolescents, the risk of overweight, obesity and WHtR $\geqslant 0.5$ was significantly higher for low SES children and adolescents. The findings are highly relevant to policy makers involved in child obesity prevention interventions and highlight the need for better targeted interventions among children and adolescents from low SES backgrounds, and adolescents in particular.

International Journal of Obesity (2017) 41, 76-82; doi:10.1038/ijo.2016.204

\section{INTRODUCTION}

The high prevalence of child obesity remains a global public health concern. ${ }^{1,2}$ In response to the increasing number of overweight and obese children, government and nongovernment agencies in many countries have invested in programs that address modifiable factors (for example, diet, physical activity and screen time) associated with obesity. The return on intervention investments appear promising with some countries reporting a stabilization in child obesity rates at a population level, ${ }^{3-8}$ but others are yet to observe evidence of a plateau. $^{9-11}$ The stabilization of child obesity rates is positive for public health, but there is strong evidence that child obesity remains unequally distributed across subgroup populations, ${ }^{12,13}$ and that in some countries obesity trends among children from socially disadvantaged backgrounds and certain ethnicities are not stabilizing. ${ }^{14-16}$ The evidence suggests that some child obesity interventions are effective; ${ }^{17-20}$ however, changing obesogenic factors is not a linear process, rather, change is time dependent and complex, and involves interactions between biology, environment and behavior. These interactions may differ across population groups, which may explain why the current interventions are not having the desired impacts in socially disadvantaged communities.

Serial population surveillance of children's obesity status is essential to monitor prevalence estimates over time to guide preventive policies and interventions, and to broadly assess the returns on investments in child obesity prevention programs. The purpose of this study was to investigate trends, and the socioeconomic distribution, of measured overweight, obesity and abdominal obesity among children aged 4-18 years between 1985 and 2015 collected by a state population surveillance program of children's weight and weight-related behaviors.

\section{MATERIALS AND METHODS}

Five representative cross-sectional surveys of children aged 4-18 years living in New South Wales (NSW; 2015 pop $7.6 \mathrm{mil}$ ), Australia, were analyzed to examine change in weight status at five time points: 1985 , 1997, 2004, 2010 and 2015. Sample size for 1985 were based on detecting a 5\% group difference with $90 \%$ power and $a 0.05$ and for 1997-20042010-2015 surveys a 10\% group difference with $80 \%$ power and $a$-level of 0.05 . All surveys were school-based and used comparable sampling frames that were based on a two-stage probability sample (school and student). The sampling frame comprised all NSW schools with the exception of

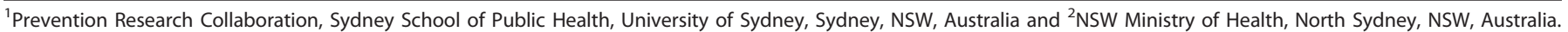

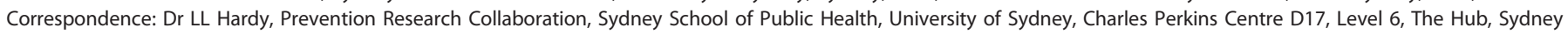
2006, NSW, Australia.

E-mail: louise.hardy@sydney.edu.au

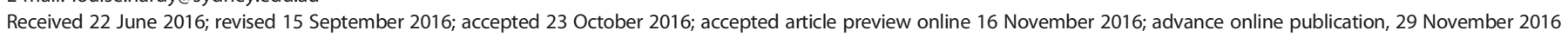


special schools (for example, blind, sport) and schools with enrollments $<180$ students (due to cost and small student numbers). Within each sector, the schools were ordered by location (based on geo-location codes to identify rural and urban schools), gender, socioeconomic status (SES) and school size. The sample of schools was therefore representative of sector (government, independent, Catholic schools), location (rural and urban), gender composition and SES. That is, the proportions of students from across the different combination of stratification variables were similar to those in the population of eligible students. The probability of school selection was proportional to size of the school enrollment. Schools were sampled from each education sector proportional to enrollment in that sector, and students from one to two randomly selected classes in each target grade were invited to participate.

The study protocols are comparable for each survey year and included information on the child's school level (primary or secondary school), sex date of birth and postcode of residence. Height $(\mathrm{m})$, weight $(\mathrm{kg})$ and waist circumference $(\mathrm{cm})$ were measured in socks, over one layer of light clothing by trained field staff using standard procedures. ${ }^{21}$ Waist circumference was measured at the level of the narrowest point between the lower intercostal border and iliac crest with a steel anthropometric tape measure. Body mass index (BMl; $\mathrm{kg} \mathrm{m}^{-2}$ ) was calculated from height and weight and children categorized as overweight and obese using the International Obesity Taskforce age-sex adjusted cut-points. ${ }^{22}$ Waist-to-height ratio (WHtR) is an indicator of abdominal obesity and was calculated as waist circumference divided by height and dichotomized as a ratio $<$ or $\geqslant 0.5^{23}$

Children's home postcode was a proxy measure of SES using the Australian Bureau of Statistics' Socioeconomic Index for Areas (SEIFA) Index of Relative Socioeconomic Disadvantage. ${ }^{24}$ SEIFA summarizes censusobtained socioeconomic indicators for geographic areas including income, educational attainment, unemployment and proportion of people in unskilled occupations. SEIFA scores from the national census most proximal to the survey year were used to rank students into low, middle and high tertiles according to SES background.

\section{Surveys}

1985 data originate from the Australian Health and Fitness Survey, 25 a national survey $(n=8484)$ of children aged 8-15 years conducted between May and October 1985. Primary and high schools were randomly selected from each education sector, stratified by state, and students were selected at random within schools. NSW data $(n=2955)$ were extracted and 1986 census data were used to determine SES. 1997 data are from the NSW Schools Fitness and Physical Activity Survey (NSWSFPAS), ${ }^{26}$ a representative NSW population survey of children aged 5-17 years in primary and high schools $(n=5518)$ conducted between February and March 1997. 1996 census data were used to determine SES. 2004-20102015 data are from the NSW Schools Physical Activity and Nutrition Survey (SPANS). ${ }^{27,28}$ SPANS are representative NSW population surveys of children aged 4-18 years, in primary and high schools (2004 $n=5402 ; 2010$ $n=8058 ; 2015 n=7557)$ conducted between February and March. 2006 census data were used to determine SES for 2004, and 2011 census data for 2010 and 2015 SES. The Australian Health and Fitness Survey was approved by the State Director General of Education, and NSWSFPAS and SPANS were approved by the University of Sydney Human Research Ethics Committee, NSW Department of Education and NSW Catholic Education Commission. For each survey, written consent by students and their care providers were required for participation.

\section{Analysis}

Data were analyzed in December 2015 using SAS Enterprise Guide (5.1; SAS Institute, Cary, NC, USA). For the analysis, children were stratified by primary and high school. The prevalence for each BMI category were calculated using PROC SURVEYFREQ, which takes into account the survey design and the clustering of data by school and year level. Overall associations between survey year and overweight, obesity and WHtR $\geqslant 0.5$ prevalence were tested using the Rao-Scott chi-square test. ${ }^{29}$ Logistic models were used to explore the relationships between the probability of being overweight, obese and $\mathrm{WH} \mathrm{tR} \geqslant 0.5$ with survey year, sex, school level and SES tertile modeled as nominal factors and age as a covariate. School and year level were identified as cluster variables in order to account for the design effect of the surveys. Interactions between survey year and sex, school level and SES tertile were calculated to assess whether the odds of being overweight, obese and $\mathrm{WH} \mathrm{tR} \geqslant 0.5$ by sex, school level or SES tertile changed differentially across the years of the surveys. The significance level was 0.05 and 0.1 for interaction terms.

\section{RESULTS}

The response rates and sociodemographic characteristics of children by survey year are shown in Table 1. In total, 27808 children participated across all survey years. BMI categorization data were available on 26801 children (96.4\%) and WHtR data were available on 26263 children (94.4\%). Figure 1 shows prevalences for overweight, obesity and $\mathrm{WH} \mathrm{tR} \geqslant 0.5$ for children in primary school by survey year and sex. The only significant change in the prevalence of overweight was between 1985 and 2015 and only among boys $(P=0.043)$ with the prevalence increasing relatively by 53 percentage points. Similarly, the only statistically significant change in the prevalence of obesity was between 1985 and 2015 where the prevalence of obesity increased more than threefold among boys $(P=0.044)$ and sixfold among girls $(P=0.006)$. The prevalence of $\mathrm{WHtR} \geqslant 0.5$ significantly changed between 1985 and 2015 in boys $(P<0.001)$ and girls $(P<0.001)$ also between 1997 and 2015 in boys $(P<0.001)$ and girls $(P<0.001)$ and between 2010 and 2015 the prevalence increased relatively by 27 percentage points among boys $(P=0.019)$.

Figure 2 shows prevalences for overweight, obesity and $\mathrm{WH} t \mathrm{R} \geqslant 0.5$ for adolescents in high school by survey year and

Table 1. Summary characteristics of the sample by survey year

\begin{tabular}{|c|c|c|c|c|c|}
\hline & \multicolumn{5}{|c|}{ Survey year } \\
\hline & 1985 & 1997 & 2004 & 2010 & 2015 \\
\hline Sample size & 1270 & 5518 & 5407 & 8058 & 7555 \\
\hline Available BMI data $(n)$ & 896 & 5402 & 5395 & 7734 & 7374 \\
\hline Available waist-to-height data $(n)$ & 1269 & 4391 & 5399 & 7850 & 7354 \\
\hline \multicolumn{6}{|l|}{ Age years (mean, range) } \\
\hline Primary school & $10.8(8.1-15.7)$ & $9.4(5.1-13.0)$ & $8.6(4.2-13.1)$ & $8.4(4.2-15.7)$ & $8.5(3.3-13.3)$ \\
\hline High school & $14.5(12.3-16.2)$ & $14.2(11.4-17.3)$ & $14.5(12.2-17.3)$ & $14.3(10.2-19.9)$ & $14.3(12.4-17.2)$ \\
\hline \multicolumn{6}{|l|}{ Socioeconomic status (\%) } \\
\hline Low & 32.1 & 27.4 & 23.9 & 29.0 & 24.5 \\
\hline Middle & 39.4 & 39.6 & 35.9 & 37.9 & 34.4 \\
\hline
\end{tabular}



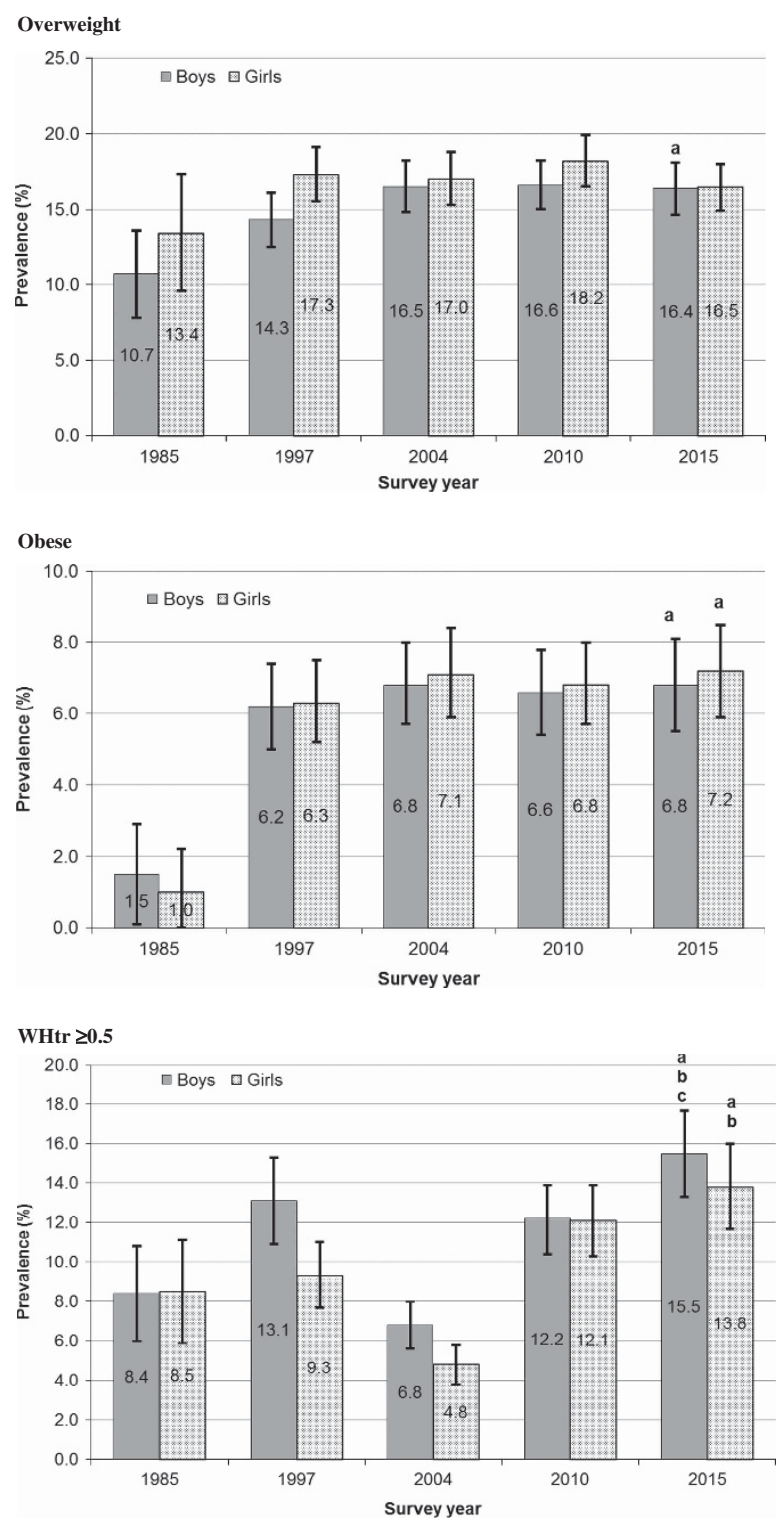

$\mathbf{a}=1985-2015 \mathrm{P}<0.05 ; \quad \mathbf{b}=1997-2015 \mathrm{P}<0.01 ; \quad \mathbf{c}=2010-2015 \mathrm{P}<0.02$

Figure 1. Prevalence $(\%, 95 \% \mathrm{Cl})$ of overweight, obese and $\mathrm{WH}$ tr $\geqslant 0.5$ among primary school children, by survey year and sex.

sex. Significant changes in the prevalence of overweight were observed between 1985 and 2015 in boys $(P=0.002)$ and girls $(P<0.001)$, between 1997 and 2015 in boys $(P=0.006)$ and girls $(P<0.001)$ and between 2010 and 2015 in boys $(P=0.021)$ and girls $(P<0.001)$. Between 2010 and 2015 the prevalence of overweight increased relatively by 20 and 38 percentage points in boys and girls, respectively. The prevalence of obesity among adolescents was very low in 1985 . The only significant change in the prevalence of obesity was between 1997 and 2015 in boys $(P=0.022)$ : a relative increase of 33 percentage points. Significant changes in the prevalence of $\mathrm{WH} t \mathrm{R} \geqslant 0.5$ were observed between 1985 and 2015 in boys $(P<0.001)$ and girls $(P=0.014)$, between 1997 and 2015 in boys $(P<0.001)$ and girls $(P=0.011)$ and between 2010 and 2015 in boys $(P<0.001)$.

Figure 3 shows the odds of children and adolescents from low SES backgrounds being overweight, obese and having abdominal obesity $(\mathrm{WHtR} \geqslant 0.5)$ at each survey time point, by school level,
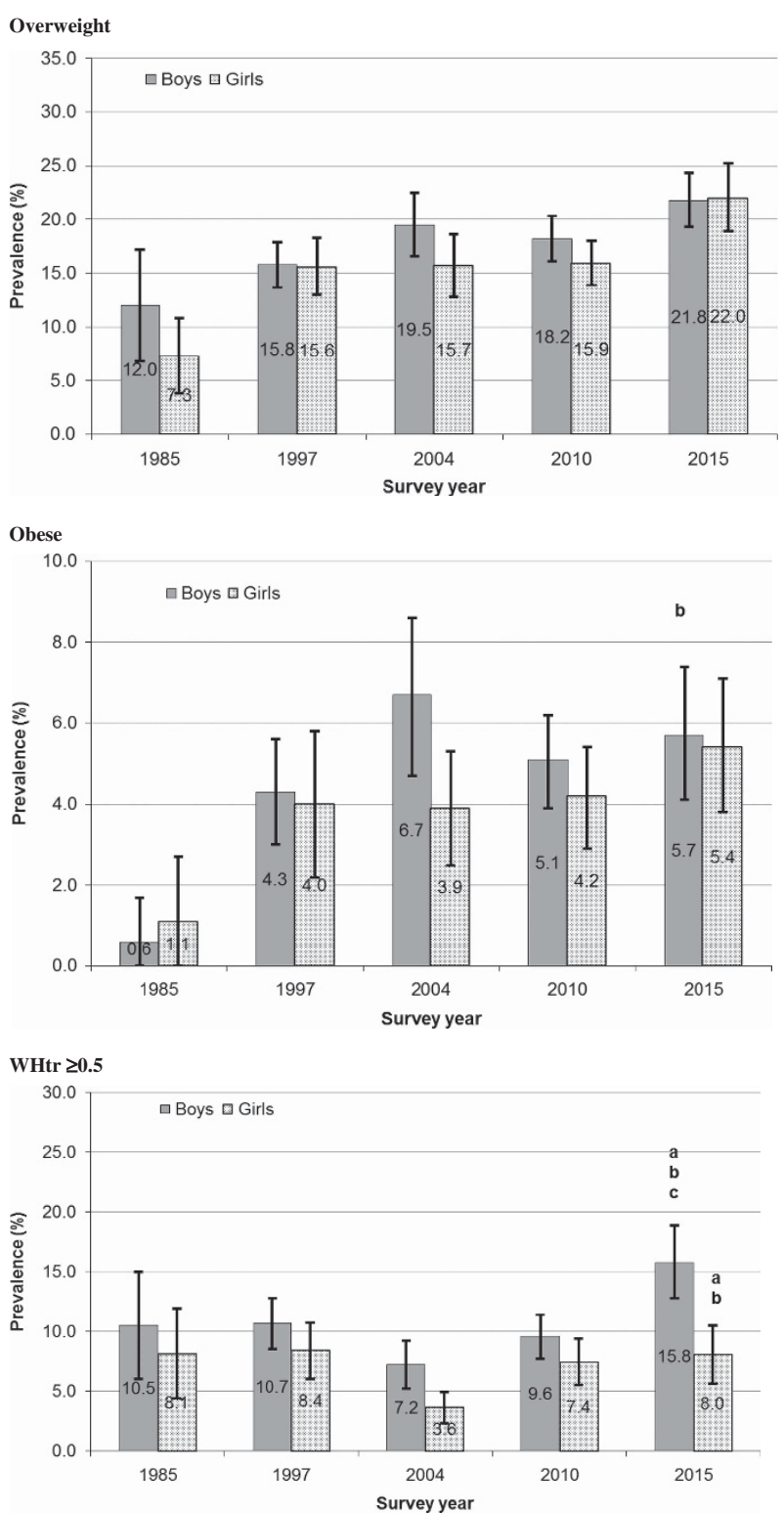

$\mathbf{a}=1985-2015 \mathrm{P}<0.01 ; \quad \mathbf{b}=1997-2015 \mathrm{P}<0.01 ; \quad \mathbf{c}=2010-2015 \mathrm{P}<0.001$

Figure 2. Prevalence $(\%, 95 \% \mathrm{Cl})$ of overweight, obese and $\mathrm{WHtR} \geqslant$ 0.5 among high school adolescents, by survey year and sex.

compared with peers from high SES backgrounds. In primary school children, the odds of being overweight were 32 and $77 \%$ higher among children from low SES backgrounds compared with children from high SES backgrounds in 2010 and 2015, respectively. In high school, SES differences in the prevalence of overweight were apparent in 2015, with the odds of overweight being 64\% higher among adolescents from low compared with high SES backgrounds.

Significant SES differences in the prevalence of obesity have been apparent among primary school children since 1997. Between 1997 and 2010, the odds of obesity were between 1.73 and 1.97 times higher among children from low, compared with children from high SES backgrounds increasing to 2.36 in 2015. Similarly, among adolescents in high school, significant SES differences in the prevalence of obesity were apparent from 2004 onwards. The odds of being obese for adolescents from low 

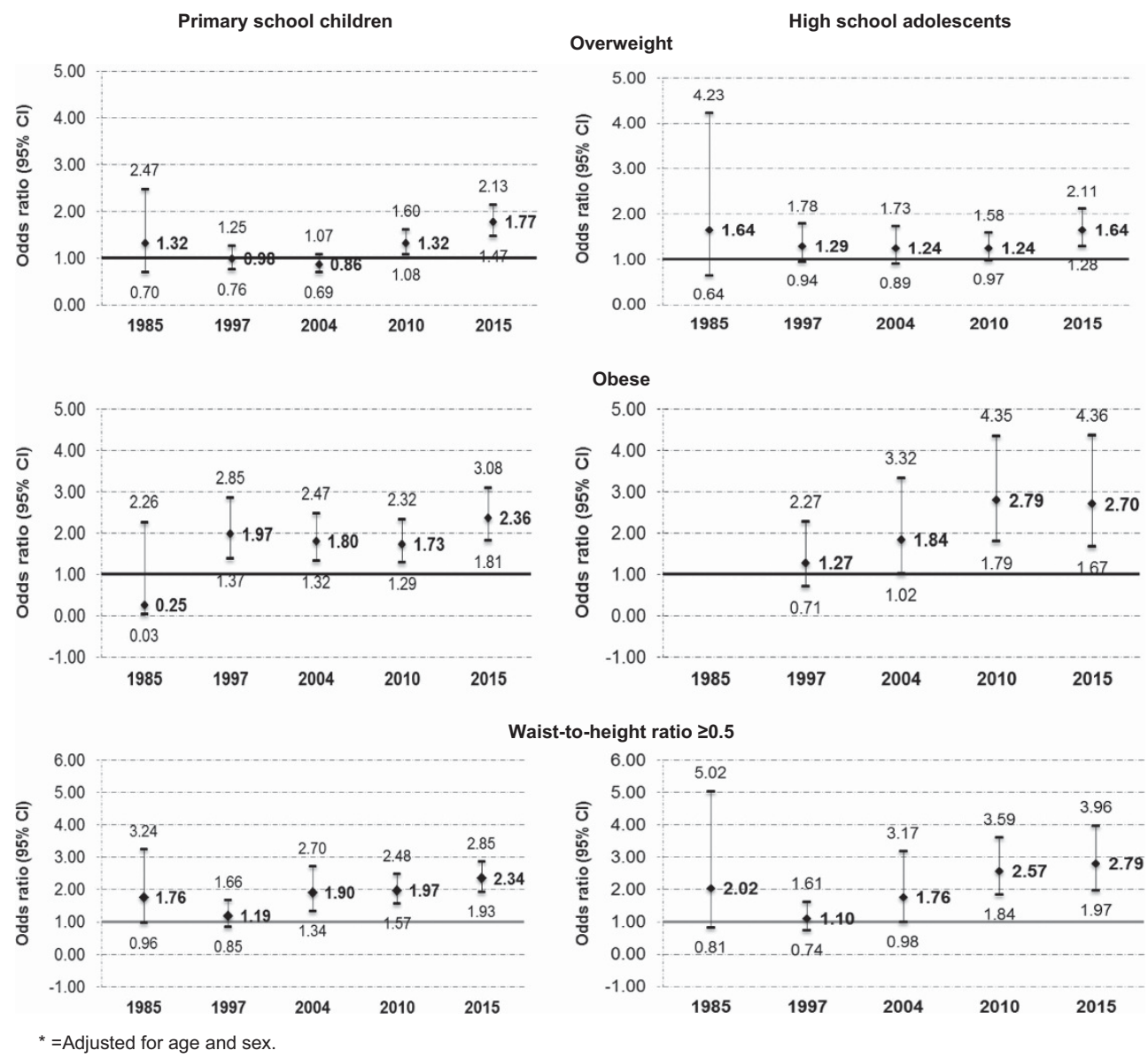

Waist-to-height ratio $\geq 0.5$

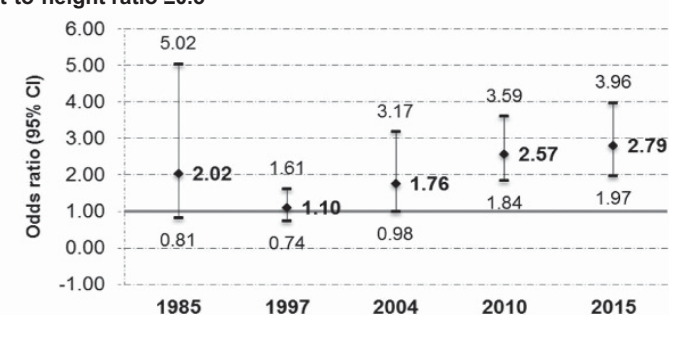

Figure 3. Odds of low SES children and adolescents being overweight, obese and having WHtR $\geqslant 0.5$, compared with high SES children adolescents.

SES backgrounds were 1.84-2.79 times higher than adolescents from high SES backgrounds.

Significant SES differences in the prevalence of $\mathrm{WHtR} \geqslant 0.5$ have been apparent among primary school children since 2004. In 2004 and 2010, the odds of WHtR $\geqslant 0.5$ were 90 and $97 \%$ higher among children from low, compared with children from high SES backgrounds with the odds increasing to 2.34 in 2015. Among adolescents in high school, significant SES differences in the prevalence of $\mathrm{WHtR} \geqslant 0.5$ were apparent from 2010 onwards. The odds of WHtR $\geqslant 0.5$ were 2.57 and 2.79 times higher in 2010 and 2015, respectively, for adolescents from low SES backgrounds compared with adolescents from high SES backgrounds.

BMI density plots of children from low and high SES backgrounds in 1997 and 2015, by school level and sex, are presented in Figure 4. In contrast to high SES children and adolescents, there is a clear temporal right shift and decreased kurtosis in the distributions for children and adolescents from low SES backgrounds, and these differences were greater among adolescents in high school compared with children in primary school. The 1997 and 2015 distributions curves are aligned closer for the high SES tertile compared with the variability between survey years of the low SES tertile.

\section{DISCUSSION}

This study reports on 30-year trends in the prevalence of overweight and obesity, and uniquely, $\mathrm{WHtR} \geqslant 0.5$ in Australian children and adolescents. In this study, overweight and obesity have not significantly increased among primary school children nor has the prevalence of obesity increased in high school adolescents since 1997, a finding that has been previously suggested. ${ }^{4}$ The addition of 2015 estimates shows that since 2010, and in contrast to primary school children, there were significant increases in the prevalence of overweight among adolescents, increasing from 17 to 22\%. While the 2015 prevalence of overweight was similar for adolescent boys and girls ( 22\%), the prevalence among girls increased by $8 \%$ after being stable at approximately $16 \%$ for the previous 18 years.

This is the first study to report on the prevalence and trends of abdominal adiposity in Australian children and adolescents. The prevalence of $\mathrm{WHtR} \geqslant 0.5$ has significantly changed between 1985 and 2015 in children and adolescents, including an increase between 2010 and 2015. With the exception of 2004, the prevalence of abdominal obesity was around twice the prevalence of obesity in primary school children and adolescent boys and approximately 30 relative percentage points higher in adolescent girls. It is not clear why $\mathrm{WHtR} \geqslant 0.5$ rates have increased and obesity rates have remained stable but the increase in abdominal obesity is of concern. BMI is a surrogate measure of total adiposity that does not distinguish between fat and fat-free mass nor does it describe body fat distribution, which may be a more important to than total adiposity. WHtR measures fat accumulation around the abdominal area, which is associated with less favorable cardiometabolic profiles in children ${ }^{30,31}$ and in adults. ${ }^{32}$ Hence, while both measure adiposity, determining which of these measures is the optimal for obesity screening is still being debated. ${ }^{33,34} \mathrm{WHtR}$ 


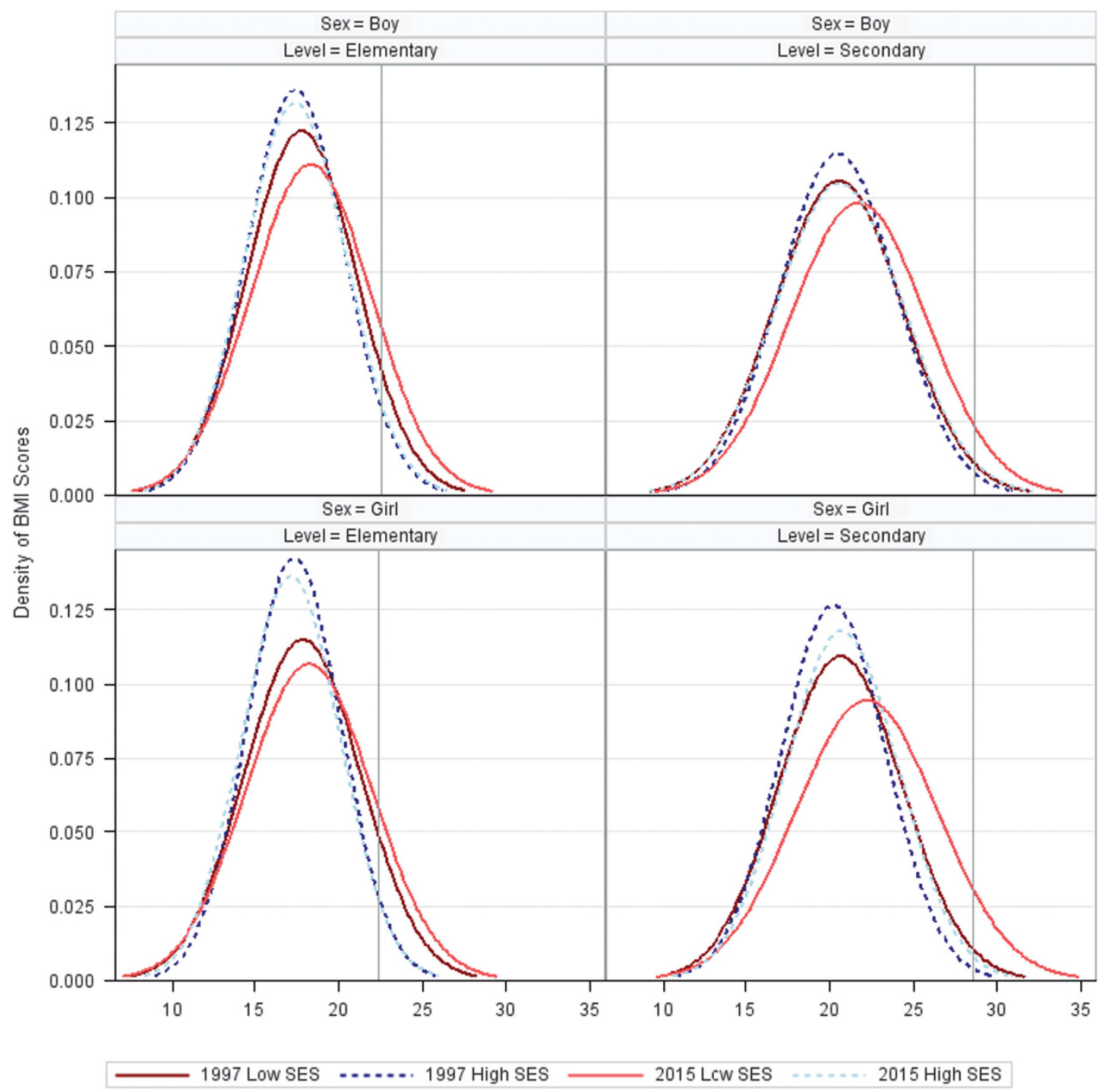

Figure 4. BMI distributions for children and adolescents from low and high SES backgrounds in 1997 and 2015 by sex and school level.

appears to add additional information in terms of discriminating obesity-related cardiometabolic risk, compared with BMI, and in children who are overweight or obese it may identify children who need medical intervention.

Alternatively the temporal increase in abdominal obesity may reflect a right shift in $\mathrm{BMI}$ distribution. We used the IOTF obese category (equivalent to a $\mathrm{BMI} \geqslant 30 \mathrm{~kg} \mathrm{~m}^{-2}$ at age 18 years); however, the proportion of Australian children in morbid obese category has significantly increased between 1985 and 2012. Children with morbid obesity (equivalent to a $\mathrm{BMI} \geqslant 35 \mathrm{~kg} \mathrm{~m}^{-2}$ at age 18 years) represented $11 \%$ of children with obesity in 1985 increasing to $23 \%$ in 2012 and children with severe obesity $\left(\mathrm{BMI} \geqslant 140 \%\right.$ of the 95th percentile or a $\left.\mathrm{BMI} \geqslant 40 \mathrm{~kg} \mathrm{~m}^{-2}\right)$ represented $19 \%$ of children with obesity in 1985 and increased to $32 \%$ in 2012 . Further research is required to examine the association between more extreme obesity categories and $W H t R \geqslant 0.5$, but the current findings suggest certain obesogenic factors are influencing abdominal obesity, especially in adolescent boys. This may reflect changes to environmental cues that influence epigenetic mechanisms that influence the distribution of fat and suggests that more research is required.
The reason for a lower $\mathrm{WH} \mathrm{tR} \geqslant 0.5$ prevalence in 2004 is not clear and further exploration of the data is required to understand this paradox. Although the field staff for each survey were trained in anthropometric measurement and their inter-rater reliability assessed, ${ }^{26-28}$ measurement error must be considered, given there was no concomitant decrease in the prevalence of obesity. We found that obesity and $\mathrm{WH} \mathrm{H} \mathrm{R} \geqslant 0.5$ were strongly and positively associated and that the majority of children and adolescents who were in the obese category also had a $\mathrm{WH} t \mathrm{R} \geqslant 0.5$. These findings are similar to a study of 14493 children aged 5-18 years, which showed children in the overweight and obese BMI categories with a $\mathrm{WHtR}<0.5$ had a cardiometabolic risk approaching that of children in the normal BMI category. In children and adolescents who are overweight and obese, an increasing WHtR was significantly associated with increased cardiometabolic risk with the greatest associations observed in children with obesity. ${ }^{31}$

A clear, consistent and concerning finding in this study was the unequal distribution of adiposity indicators within survey years, between children and adolescent from low SES, compared with peers from high SES backgrounds. Overall, the prevalence was significantly higher among children and adolescents from low SES compared with peers from the high SES backgrounds, especially 
for obesity and $W H t R \geqslant 0.5$. Differences in the prevalence of overweight between low and high SES children and adolescent began in 2010, and in 2004 for abdominal obesity among primary school girls, while the difference for obesity rates in children began in 1997 and 2004 among adolescents. The increasing SES disparities in obesity and abdominal obesity are especially concerning and suggest that urgent intervention is needed in low SES populations. Australia is not alone in identifying SES disparities in children and adolescents with studies in the US ${ }^{35}$ and Europe ${ }^{36}$ recently reporting similar findings of social inequality in child overweight and obesity.

While many factors are involved in the increase in overweight and obesity, including biology, there is strong evidence on the adverse impact of the obesogenic environment on lifestyle behaviors. ${ }^{37,38}$ Australia has being making substantial investment to address the issue of obesity since $1997 .{ }^{39}$ Obesity intervention mapping tools are available; ${ }^{40}$ however, within the real-world situation there is no system that accurately documents obesity prevention programs delivered across multiple sectors and settings. It is, however, reasonable to consider that the background influence of the up-stream policy has contributed to change in children and adolescent's weight status. In NSW, investment in child obesity prevention strategies has remained a government priority with establishment of linkages between academic sectors and the health system to coordinate investments across agencies and sectors. ${ }^{41,42}$

The evidence indicates the need to invest in the childhood years (that is, birth to age 12 years) to influence the prevention of unhealthy weight gain and to reduce the burden of chronic disease and future medical costs. ${ }^{43,44}$ Hence, much of the investment in NSW has focused on the early childhood and primary school years; and the current findings suggest some success from that investment. Our findings show that the prevalence of overweight and of obesity have remained stable among primary school children since 1997, but not among adolescents (high school) where the prevalence of overweight has significantly increased between 2010 and 2015. The implementation of child obesity prevention programs in NSW began around 2006 and was primarily targeted within the primary school setting. Hence, the increase in overweight among adolescents may reflect the lack of investment in this age group, who would have received only minimal exposure to primary school-based obesity prevention initiatives. The increase and higher prevalence of overweight in adolescents is worrying given the strong evidence of the tracking of BMI from adolescence into adulthood. ${ }^{45,46}$

Although inter-country prevalence comparisons are difficult because of difference in BMI categorization systems and data presentations, the 2015 rates presented here suggest that rates of obesity are lower than those of US ${ }^{6}$ and UK ${ }^{3}$ children. Similarly, the overall prevalence of abdominal obesity in 2015 was 13.9\%, which was substantially lower than the US prevalence of 32.9\% in 2012 for similarly aged children. ${ }^{47,48}$

Study strengths include comparable survey methods, large representative samples of children, measured anthropometry, and trained field staff using standard protocols and quality control procedures to ensure reliability. A potential limitation is the response rate; however, these have remained relatively constant over time, usually greater than $60 \%$, and are higher than similar school based ${ }^{49}$ and household ${ }^{48}$ surveys of Australian children's weight status. Earlier research examining non-response bias in the 2004 survey suggested there was no difference in the prevalence of overweight and obesity between participating and nonparticipating students. ${ }^{50}$ Ethics restrictions prevent routine examination of non-responder bias at each survey point, which raises the issue of whether population surveillance surveys which benefit public health should have passive (that is, opt-out) rather than active consent. Finally, our sampling frame was designed to be representative of NSW children, and while NSW is Australia's most populous state, the findings may not necessarily be generalizable to all Australian children.

\section{CONCLUSION}

Since 1997, the prevalence of overweight and obesity has not significantly changed in children, nor has the prevalence of obesity significantly changed since 1997 in adolescents. Conversely the prevalence of overweight has significantly changed across survey periods in adolescents, with significant increases observed between 2010 and 2015. Abdominal obesity, a marker of cardiometabolic risk, has significantly increased between 1985 and 2015 and prevalence rates at each survey time point are around twice that of obesity. There are clear and persistent SES inequalities in the distribution of overweight, obesity and WHtR, with children and adolescents from low SES backgrounds more likely to be in unhealthy weight categories and this disparity has increased over time. This finding suggests that the current delivery of obesity prevention programs to socially disadvantaged areas is either not adequately reaching into these communities, or the programs do not address the necessary obesogenic factors need to ameliorate the social gap in obesity prevalence.

\section{CONFLICT OF INTEREST}

The authors declare no conflict of interest.

\section{ACKNOWLEDGEMENTS}

The 1985 Australian Health and Fitness Survey (AHFS) was funded by the Commonwealth Department of Sport, Recreation and Tourism, National Heart Foundation of Australia, Commonwealth Schools Commission and the Commonwealth Department of Health. The 1997 NSWSFPAS was funded by the NSW Department of School Education, the National Development Program and the NSW Department of Health. We thank the schools and students for their participation. BAD was employed by the NSW Ministry of Health on the Biostatistical Officer Training Program at the time this work was conducted. LLH had full access to all of the data in the study and takes responsibility for the integrity of the data and the accuracy of the data analysis. This work was funded by NSW Ministry of Health.

\section{REFERENCES}

1 Lobstein T, Jackson-Leach R, Moodie ML, Hall KD, Gortmaker SL, Swinburn BA et al. Child and adolescent obesity: part of a bigger picture. Lancet 2015; 385: 2510-2520.

2 World Health Organization. Report of the Commission on Ending Childhood Obesity. World Health Organization: Geneva, 2016.

3 van Jaarsveld $\mathrm{CH}$, Gulliford MC. Childhood obesity trends from primary care electronic health records in England between 1994 and 2013: population-based cohort study. Arch Dis Child 2015; 100: 214-219.

4 Olds TS, Tomkinson GR, Ferrar KE, Maher CA. Trends in the prevalence of childhood overweight and obesity in Australia between 1985 and 2008. Int J Obes (Lond) 2010; 34: 57-66.

5 de Wilde JA, Verkerk PH, Middelkoop BJ. Declining and stabilising trends in prevalence of overweight and obesity in Dutch, Turkish, Moroccan and South Asian children 3-16 years of age between 1999 and 2011 in The Netherlands. Arch Dis Child 2014; 99: 46-51.

6 Ogden $\mathrm{CL}$, Carroll MD, Kit BK, Flegal KM. Prevalence of childhood and adult obesity in the United States, 2011-2012. JAMA 2014; 311: 806-814.

7 Leal DB, de Assis MAA, González-Chica DA, da Costa FF. Trends in adiposity in Brazilian 7-10-year-old schoolchildren: evidence for increasing overweight but not obesity between 2002 and 2007. Ann Hum Biol 2014; 41: 255-262.

8 Lazzeri G, Panatto D, Pammolli A, Azzolini E, Simi R, Meoni V et al. Trends in overweight and obesity prevalence in Tuscan schoolchildren (2002-2012). Public health nutr 2015; 18: 3078-3085.

9 Savva SC, Kourides YA, Hadjigeorgiou C, Tornaritis MJ. Overweight and obesity prevalence and trends in children and adolescents in Cyprus 2000-2010. Obes Res Clin Pract 2014; 8: e426-e434.

10 Sigmundova D, Sigmund E, Hamrik Z, Kalman M. Trends of overweight and obesity, physical activity and sedentary behaviour in Czech schoolchildren: HBSC study. Eur J Public Health 2014; 24: 210-215. 
11 Ma L, Zhu Y, Mai J, Jing J, Liu Z, Jin Y et al. Secular trends in overweight and obesity among urban children in Guangzhou China, 2007-2011. Iran J Public Health 2015; 44: 36-42.

12 Bammann K, Gwozdz W, Lanfer A, Barba G, De Henauw S, Eiben G et al. Socioeconomic factors and childhood overweight in Europe: results from the multicentre IDEFICS study. Pediatr Obes 2013; 8: 1-12.

13 Shrewsbury V, Wardle J. Socioeconomic status and adiposity in childhood: a systematic review of cross-sectional studies 1990-2005. Obesity (Silver Spring) 2008; 16: 275-284.

14 Miqueleiz E, Lostao L, Ortega P, Santos JM, Astasio P, Regidor E. Trends in the prevalence of childhood overweight and obesity according to socioeconomic status: Spain, 1987-2007. Eur J Clin Nutr 2014; 68: 209-214.

15 Pan L, McGuire LC, Blanck HM, May-Murriel AL, Grummer-Strawn LM. Racial/ethnic differences in obesity trends among young low-income children. Am J Prev Med 2015; 48: 570-574.

16 Pan L, May AL, Wethington H, Dalenius K, Grummer-Strawn LM. Incidence of obesity among young US children living in low-income families, 2008-2011. Pediatrics 2013; 132: 1006-1013.

17 Wang Y, Cai L, Wu Y, Wilson RF, Weston C, Fawole O et al. What childhood obesity prevention programmes work? A systematic review and meta-analysis. Obes Rev 2015; 16: 547-565.

18 Sobol-Goldberg S, Rabinowitz J, Gross R. School-based obesity prevention programs: a meta-analysis of randomized controlled trials. Obesity 2013; 21: 2422-2428.

19 Bleich SN, Segal J, Wu Y, Wilson R, Wang Y. Systematic review of communitybased childhood obesity prevention studies. Pediatrics 2013; 132: e201-e210.

20 Cai L, Wu Y, Cheskin LJ, Wilson RF, Wang Y. Effect of childhood obesity prevention programmes on blood lipids: a systematic review and meta-analysis. Obes Rev 2014; 15: 933-944.

21 Olds T, Norton K. Anthropometrica: A Textbook of Body Measurement for Sports and Health Courses. UNSW Press: Sydney, Australia, 1996.

22 Cole T, Lobstein T. Extended international (IOTF) body mass index cut-offs for thinness, overweight and obesity. Pediatr Obes 2012; 7: 284-294.

23 Brambilla P, Bedogni G, Heo M, Pietrobelli A. Waist circumference-to-height ratio predicts adiposity better than body mass index in children and adolescents. Int $J$ Obes 2013; 37: 943-946.

24 Australian Bureau of Statistics. Census of Population and Housing: Socio-Economic Indexes for Areas (SEIFA), Australia-Data only, 2011. Catno2033055001 - [Internet]. 2013 3/13/2015. Available from http://www.abs. gov.au/AUSSTATS/abs@.nsf/DetailsPage/2033.0.55.0012006?OpenDocument.

25 Pyke JE. The Australian Health and Fitness Survey 1985: The Fitness, Health and Physical Performance of Australian School Students Aged 7-15 Years. Australian Council for Health, Physical Education and Recreation: Adelaide, Australia, 1987.

26 Booth M, Macaskill P, McLellan L, Phongsavan P, Okely T, Patterson J et al. NSW schools fitness and physical activity survey 1997. Ryde, 1997.

27 Booth ML, Okely AD, Denney-Wilson E, Hardy LL, Yang B, Dobbins T NSW Schools Physical Activity and Nutrition Survey (SPANS) 2004: Full Report. Sydney, 2006.

28 Hardy LL, King L, Espinel P, Cosgrove C, Bauman A. NSW Schools Physical Activity and Nutrition Survey (SPANS) 2010; Full Report. Sydney, 2011.

29 Rao JNK, Scott AJ. On chi-squared tests for multiway contingency tables with cell proportions estimated from survey data. Ann Stat 1984; 12: 46-60.

30 Daniels SR, Morrison JA, Sprecher DL, Khoury P, Kimball TR. Association of body fat distribution and cardiovascular risk factors in children and adolescents. Circulation 1999; 99: 541-545.

31 Khoury M, Manlhiot C, McCrindle BW. Role of the waist/height ratio in the cardiometabolic risk assessment of children classified by body mass index. J Am Coll Cardiol 2013; 62: 742-751.

32 Ashwell M, Gunn P, Gibson S. Waist-to-height ratio is a better screening tool than waist circumference and BMI for adult cardiometabolic risk factors: systematic review and meta-analysis. Obes Rev 2012; 13: 275-286.

33 Wicklow BA, Becker A, Chateau D, Palmer K, Kozyrskij A, Sellers EA. Comparison of anthropometric measurements in children to predict metabolic syndrome in adolescence: analysis of prospective cohort data. Int J Obes (Lond) 2015; 39: 1070-1078.

34 Sardinha LB, Santos DA, Silva AM, Grontved A, Andersen LB, Ekelund U. A comparison between $\mathrm{BMI}$, waist circumference, and waist-to-height ratio for identifying cardio-metabolic risk in children and adolescents. PLoS One 2016; 11: e0149351.

35 Watts AW, Mason SM, Loth K, Larson N, Neumark-Sztainer D. Socioeconomic differences in overweight and weight-related behaviors across adolescence and young adulthood: 10-year longitudinal findings from Project EAT. Prev Med 2016; 87: 194-199.

36 Knai C, Lobstein T, Darmon N, Rutter H, McKee M. Socioeconomic patterning of childhood overweight status in Europe. Int J Environ Res Public Health 2012; 9: 1472-1489.

37 Gortmaker SL, Swinburn BA, Levy D, Carter R, Mabry PL, Finegood DT et al. Changing the future of obesity: science, policy, and action. Lancet 2011; 378: 838-847.

38 Swinburn BA, Sacks G, Hall KD, McPherson K, Finegood DT, Moodie ML et al. The global obesity pandemic: shaped by global drivers and local environments. Lancet 2011; 378: 804-814.

39 National Health and Medical Research Council. Acting on Australia's Weight: A Strategic Plan for the Prevention Overweight and Obesity. Commonwealth of Australia: Canberra, 1997.

40 Sacks G, Swinburn B, Lawrence M. Obesity policy action framework and analysis grids for a comprehensive policy approach to reducing obesity. Obes Rev 2009; 10: 76-86.

41 NSW Government. Prevention of Obesity in Children and Young People: NSW Government Action Plan 2003-2007. NSW Health: Sydney, 2003.

42 NSW Government. NSW Making it Happen Sydney: NSW Government; 2016 [12/04/2016]. Available from https://www.nsw.gov.au/making-it-happen.

43 Gortmaker SL, Wang YC, Long MW, Giles CM, Ward ZJ, Barrett JL et al. Three interventions that reduce childhood obesity are projected to save more than they cost to implement. Health Aff (Millwood) 2015; 34: 1932-1939.

44 Trasande L. How much should we invest in preventing childhood obesity? Health Aff (Millwood) 2010; 29: 372-378.

45 Deshmukh-Taskar P, Nicklas TA, Morales M, Yang SJ, Zakeri I, Berenson GS. Tracking of overweight status from childhood to young adulthood: the Bogalusa Heart Study. Eur J Clin Nutr 2005; 60: 48-57.

46 Fuentes RM, Notkola IL, Shemeikka S, Tuomilehto J, Nissinen A. Tracking of body mass index during childhood: a 15-year prospective population-based family study in eastern Finland. Int J Obes Relat Metab Disord 2003; 27: 716-721.

47 Xi B, Mi J, Zhao M, Zhang T, Jia C, Li J et al. Trends in abdominal obesity among US children and adolescents. Pediatrics 2014; 134: e334-e339.

48 Commonwealth Scientific Industrial Research Organisation (CSIRO) Preventative Health National Research Flagship University of South Australia. 2007 Australian National Children's Nutrition and Physical Activity Survey-Main Findings. CSIRO: Canberra, 2008. Report No.: P3 - 4592.

49 Centre for Epidemiology and Biostatistics. New South Wales school students Health behaviours survey: 2014 Report. Sydney: NSW Health, 2016.

50 Booth ML, Okely AD, Denney-Wilson I. Validation and application of a novel method of measuring non-response bias in school-based surveys of paediatric overweight and obesity. Int J Pediatr Obes 2011; 6: e87-e93.

(c) (i) $(-)$ This work is licensed under a Creative Commons Attributioncc. NonCommercial-NoDerivs 4.0 International License. The images or other third party material in this article are included in the article's Creative Commons license, unless indicated otherwise in the credit line; if the material is not included under the Creative Commons license, users will need to obtain permission from the license holder to reproduce the material. To view a copy of this license, visit http:// creativecommons.org/licenses/by-nc-nd/4.0/

(c) The Author(s) 2017 